\title{
TINJAUAN PELAKSANAAN PENGODEAN DIAGNOSIS PENYAKIT PADA PASIEN RAWAT JALAN DI RSUD TUGUREJO PROVINSI JAWA TENGAH
}

\author{
Qisthi Qurrota A'yuni ${ }^{1}$, Kori Puspita Ningsih ${ }^{2 *}$ \\ 1, *2Diploma DIII Rekam Medis dan Informasi Kesehatan Stikes Jenderal Achmad Yani Yogyakarta, JI Ring \\ Road Barat Ambarketawang Gamping Sleman, email kori_puspita@yahoo.co.id
}

\begin{abstract}
Background: The implementation of diagnosis coding in the Medical Record Unit at a health institution plays an important role in the administration of medical records at the hospital because it describes the quality management of medical records. In order to maintain the quality, it is crucial to accomplish the accreditation standard, especially at ICM. 13 related coding.

Objective: This study aimed to understand the procedures of implementation, compliance disease diagnosis code execution in an outpatient based on accreditation standards KARS 2012, the percentage and the resistance of diagnosis coding implementation in outpatients.

Methods: This research was a descriptive qualitative approach with cross sectional design. The subjects were medical records staff with Diploma 3 medical record education background, outpatients coding officer, reporting coordinator, the head of clinic space and a clinic nurse. The data collectin techniques used were observation, documentation and interview studies. Testing the validity of the data use triangulate of source and triangulate of techniq.

Results: The coding was done by the medical records staffs and nurses, coding reference were in the form of policies, guidelines and standard operating procedure, guidelines used by nurses in coding was assistive book. Tugurejo Hospital Accreditation in Central Java province had fulfilled the five elements of ICM. 13 and passed the accreditation of type B-level plenary meeting. The percentage of outpatient coding implementation reached $78.6 \%$, consisting of JKN amounted to $75.4 \%$ and $3.2 \%$ were non JKN. The barriers of coding implementation consists of five elements such as man, method, material, machine and money.

Conclusion: In general the implementation of the coding in JKN outpatient has already done optimally, but for non JKN has not been optimal because of the inhibiting factors such as man, method, material, machine and money.
\end{abstract}

Keywords: coding, disease diagnosis, outpatient

\section{PENDAHULUAN}

Pelaksanaan pengodean diagnosis di Instalasi Rekam Medis pada suatu institusi kesehatan memegang peranan penting dalam penyelenggaraan rekam medis di suatu rumah sakit karena menggambarkan pengolahan rekam medis yang bermutu. Selain itu pengodean diagnosis penyakit yang telah dikode akan digunakan untuk keperluan pembuatan indeks penyakit dan kemudian dibuat laporan morbiditas, sehingga datanya akan berpengaruh pada penyajian informasi untuk menunjang fungsi perencanaan, manajemen, riset di bidang kesehatan yang hasil akhirnya untuk pengambilan keputusan yang bijak.

Guna menjaga kualitas mutu pelayanan, khususnya pada pelaksanaan pengodean diagnosis, maka diperlukan akreditasi rumah sakit. ${ }^{1}$ Rumah sakit harus menggunakan standar kode diagnosa, kode prosedur atau tindakan, simbol, singkatan dan definisi. $^{2}$ Dengan adanya standar pengodean pada akreditasi maka rumah sakit 
lebih menjamin ketepatan pengodean sesuai prosedur yang ditetapkan.

Salah satu yang mempengaruhi ketepatan pengodean diagnosis adalah sumber daya manusianya. Salah satu wewenang perekam medis dan informasi kesehatan yaitu melaksanakan sistem klasifikasi dan kodifikasi penyakit yang berkaitan dengan kesehatan dan tindakan medis sesuai terminologi medis yang benar. ${ }^{3}$

Dengan adanya tanggung jawab coder dalam menunjang pelaksanaan pengodean diagnosis penyakit disuatu rumah sakit, maka apabila dalam pelaksanaannya belum sesuai regulasi akan berdampak pada ketidaktepatan laporan morbiditas rumah sakit dan ketidakakuratan data penyakit yang berpengaruh pada ketepatan pengambilan keputusan pimpinan di suatu rumah sakit.

\section{BAHAN DAN CARA PENELITIAN}

Jenis penelitian ini adalah deskriptif kualitatif dengan rancangan penelitian cross sectional. Penelitian ini dilakukan di RSUD Tugurejo Provinsi Jawa Tengah.

Objek pada penelitian ini adalah kebijakan pelayanan rekam medis, pedoman pelayanan rekam medis terkait prosedur pengodean dan kualifikasi jabatan, uraian tugas (job description) petugas coding, SPO terkait pelaksanaan pengodean diagnosis penyakit untuk pasien JKN dan Non JKN, data rekapitulasi diagnosis penyakit pasien rawat jalan, formulir bukti pelayanan rawat jalan JKN kesehatan dan dokumen rekam medis rawat jalan. Adapun subjek pada penelitian ini meliputi, staf rekam medis berlatar belakang D3 rekam medis yang diberi wewenang oleh Kepala Instalasi Rekam Medis untuk melakukan triangulasi sumber, petugas coding rawat jalan, koordinator pengolahan rekam medis, kepala ruang poliklinik dan perawat klinik.

Pengumpulan data pada penelitian ini dengan melakukan observasi, studi dokumentasi dan wawancara. Instrumen yang digunakan untuk pengambilan data menggunakan check list observasi, check list studi dokumentasi, pedoman wawancara, alat tulis dan kamera/recorder. Peneliti melakukan pemeriksaan keabasahan data pada penelitian ini dengan triangulasi sumber dan triangulasi teknik. Metode analisis data yang digunakan selama penelitian meliputi data reduction (reduksi data), data display (penyajian data) dengan menggunakan tabel dan grafik dan tahap tarakhir conclusion drawing atau verification (menarik kesimpulan atau verifikasi).

\section{HASIL DAN PEMBAHASAN}

Pelaksaaan pengodean diagnosis berdasarkan aspek Man (SDM): Dari hasil observasi, petugas pelaksana pengodean diagnosis penyakit pada pasien rawat jalan dibagi menjadi pasien rawat jalan JKN dan non JKN. Pada pasien rawat jalan JKN, pengodean dilakukan oleh petugas coding 
yang berlatar belakang D3 rekam medis berjumlah 3 orang, sedangkan untuk pasien rawat jalan non JKN pengodean dilakukan oleh perawat di masing-masing klinik yang berjumlah 21 orang.

Salah satu wewenang Ahli Madya Rekam Medis dan Informasi Kesehatan adalah melaksanakan sistem klasifikasi dan kodefikasi penyakit yang berkaitan dengan kesehatan dan tindakan medis sesuai terminologi medis yang benar ${ }^{3}$. Sebetulnya perawat mempunyai tugas dan wewenang sendiri dalam melakukan pelayanan kepada pasien. Perawat ranahnya lebih kontak langsung menangani pasien, bukan melakukan pelayanan administratif. Perawat berwewenang sebagai pemberi asuhan keperawatan, penyuluh dan konselor bagi klien, pengelola pelayanan keperawatan, peneliti keperawatan dan lain sebagainya. ${ }^{4}$

\section{Dari segi Method (cara): Kebijakan} pelaksanaan pengodean diagnosis penyakit pada pasien rawat jalan di RSUD Tugurejo sudah ada, berdasarkan SK Direktur RSUD Tugurejo Provinsi Jawa Tengah Nomor 445.61/030e/2015 tentang Kebijakan Pelayanan Instalasi Rekam Medis RSUD Tugurejo Provinsi Jawa Tengah Provinsi Jawa Tengah. Namun kebijakan tersebut masih bersifat umum, tidak spesifik kebijakan yang terkait pasien JKN dan non JKN dan pelaksanaan dari kebijakan tersebut masih belum optimal dilakukan.Kebijakan adalah sebuah ketetapan yang berlaku, dicirikan oleh perilaku yang konsisten dan berulang, baik dari yang membuat atau yang melaksanakan kebijakan tersebut. ${ }^{5}$

Acuan pelaksanaan pengodean juga diatur di pedoman pelayanan rekam medis terkait pengodean diagnosis penyakit dan pedoman pelayanan rekam medis terkait kualifikasi jabatan RSUD Tugurejo Provinsi Jawa Tengah Nomor 03.05///2949/2012. Keduanya sudah ada di Instalasi Rekam Medis rumah sakit tersebut. Namun untuk pelaksanaanya, berdasarkan observasi peneliti, pedoman pelayanan rekam medis terkait pengodean belum seluruhnya mengacu pada pedoman yang ada, dikarenakan masih ada yang menggunakan selain ICD-10 dan tanggung jawabnya belum seluruhnya diberikan kepada Instalasi Rekam Medis, karena masih ada bagian keperawatan yang ikut andil dalam pelaksanaan pengodean. Pedoman adalah naskah dinas yang memuat acuan yang bersifat umum di lingkungan instansi pemerintah yang perlu dijabarkan ke dalam petunjuk operasional teknis dan penerapannya disesuaikan dengan karakteristik instansi organisasi yang bersangkutan. $^{6}$

Terdapat SPO No 05/SPO/00/A048 tahun 2014 di RSUD Tugurejo Provinsi Jawa Tengah yang menjelaskan terkait pelaksanaan pengodean diagnosis penyakit rawat jalan JKN sudah, namun untuk pengodean diagnosis pasien non 
JKN belum ada. Sehingga dalam pelaksanaannya yang sudah optimal dilakukan adalah pengodean pasien rawat jalan JKN, sedangkan pasien non JKN belum dilakukan pengodean secara maksimal, karena memang tidak ada acuan dalam melakukan pengodean diagnosis rawat jalan non JKN dan alur kerjanya pun menjadi kurang jelas. Sebetulnya perlu sebuah instansi kesehatan yang mengutamakan pelayanan kepada pasien, tentu di dalamnya banyak pekerjaan yang harus diselesaikan. Oleh karena itu kebijakan, pedoman dan SPO, ketiganya penting sebagai acuan dalam melakukan suatu pekerjaan, agar berjalan secara optimal dan sebagaimana mestinya, hasilnya pun sesuai dengan target atau tujuan dari kegiatan tersebut.

Material (bahan): pedoman yang digunakan dalam pengodean rawat jalan berdasarkan hasil pengamatan yaitu petugas coding telah menggunakan ICD10 elektronik dari WHO tahun 2005 yang nantinya akan dimasukkan ke dalam system bridging INA-CBG'S, sedangkan perawat melakukan pengodean menggunakan buku bantu yang berisi kode-kode diagnosis yang sering muncul dan sering ditulis oleh dokter. ICD-10 diberlakukan secara nasional di Indonesia sebagai acuan yang digunakan di Indonesia untuk mengode diagnosis. ${ }^{7}$

Selanjutnya dari segi Machine (alat): alat yang digunakan untuk menunjang pelaksanaan pengodean rawat jalan adalah system bridging INA-CBG'S untuk penjamin JKN, yang sebelumnya dilakukan pengodean secara manual yaitu dengan melakukan pengodean terlebih dahulu pada kolom ICD-10 pada formulir bukti pelayanan JKN. Sedangkan untuk penjamin non JKN dilakukan pengodean secara langsung elektronik pada SIMRS RSUD Tugurejo Provinsi Jawa Tenga.

System bridging INA-CBG'S dan SIMRS RSUD Tugurejo Provinsi Jawa Tengah merupakan salah satu alat pencatatan rekam medis berbasis elektronik yang digunakan dalam kegiatan pengodean. Rekam medis dibagi atas dua jenis yaitu rekam medis konvensional dan rekam medis elektronik. Jenis konvensional merupakan jenis yang masih banyak dipergunakan di setiap rumah sakit seperti pencatatan secara langsung oleh tenaga kesehatan. Sedangkan jenis elektronik merupakan sistem pencatatan informasi dengan menggunakan peralatan yang modern seperti komputer atau alat elektronik lainnya. $^{8}$

Kemudian berdasarkan aspek money (finansial) petugas coding mendapatkan tunjangan secara rutin berupa tunjangan gaji, tunjangan profesi 
pendidik dan tunjangan jaminan pensiun, namun hal itu berlaku untuk seluruh staf, bukan hanya petugas pengodean saja. Adapun pemberian tunjangan tersebut secara rutin telah dilaksanakan. Sedangkan untuk penilaian kinerja staf belum menerapkan sistem reward dan punishment.

Untuk meningkatkan kinerja pegawai perlu adanya dukungan manajemen, meliputi, mengoptimalkan pemanfaatan keunggulan dan potensi kerja, mendorong pekerja untuk terus meningkatkan kemampuan, membuka kesempatan yang luas bagi pekerja untuk meningkatkan kemampuan, membantu pekerja dalam kesulitan melaksanakan tugas, membangun motivasi kerja, disiplin kerja dan etos kerja, yaitu menciptakan variasi penugasan, membuka tantangan baru, memberikan penghargaan dan insentif, membangun komunikasi dua arah. $^{9}$

Berdasarkan hasil studi dokumentasi peneliti di RSUD Tugurejo Provinsi Jawa Tengah dalam kaitannya dengan akreditasi versi 2012 terkait pengodean, untuk pemenuhan dari 5 elemen penilaian MKI. 13 sudah terpenuhi semua dan akreditasi versi 2012 telah dilaksanakan pada tahun 2014, lulus dengan tipe B tingkat paripurna. Rumah Sakit harus menggunakan standar kode diagnosa, kode prosedur atau tindakan, simbol, singkatan dan definisi dalam pemenuhan dokumen akreditasi yaitu ada 5 elemen penilaian MKI. $13 .^{10}$

Tabel Tabel 1 Hasil Studi Dokumentasi Pemenuhan MKI. 13 Terkait Kode Diagnosis Penyakit Rawat Jalan Berdasarkan Akreditasi KARS 2012

\begin{tabular}{|c|c|c|c|}
\hline $\begin{array}{c}\text { No } \\
\text {. }\end{array}$ & $\begin{array}{c}\text { Elemen Penilaian } \\
\text { MKI. 13 }\end{array}$ & $\mathbf{A}$ & Keterangan \\
\hline 1. & $\begin{array}{lr}\text { Standarisasi } & \text { kode } \\
\text { diagnosis } & \text { yang } \\
\text { digunakan } & \text { dan } \\
\text { penggunanya } & \\
\text { dimonitor } & \\
\text { (Dokumen } & \text { Kode } \\
\text { diagnosis) } & \end{array}$ & $\sqrt{ }$ & $\begin{array}{lr}\text { Kebijakan } & \text { Pelayanan } \\
\text { Instalasi Rekam Medis } \\
\text { SK. Direktur RSUD } \\
\text { Tugurejo Provinsi Jawa } \\
\text { Tengah } \\
\text { 445.61/030e/2015. Nomor } \\
\text { SPO pemberian kode } \\
\text { diagnosis menggunakan } \\
\text { ICD-10 pada formulir } \\
\text { bukti pelayanan rawat jalan } \\
\text { BPJS. } \\
\text { No. 05/SPO/00/A-048 } \\
\text { tahun 2014. } \\
\text { Pedoman pelayanan rekam } \\
\text { medis terkait pelaksanaan } \\
\text { pengodean r RSUD } \\
\text { Tugurejo Provinsi Jawa } \\
\text { Tengah Nomor } \\
\text { 03.05/I/2949/2012. }\end{array}$ \\
\hline 2. & $\begin{array}{l}\text { Standarisasi kode } \\
\text { prosedur/ tindakan } \\
\text { yang digunakan dan } \\
\text { penggunanya } \\
\text { dimonitor } \\
\text { (Dokumen kode } \\
\text { prosedur/tindakan) }\end{array}$ & $\sqrt{ }$ & $\begin{array}{l}\text { SPO pemberian kode } \\
\text { prosedur/tindakan } \\
\text { menggunakan ICD-9-CM } \\
\text { pasien rawat jalan Nomor } \\
\text { 05/SPO/00/49 tahun } 2014\end{array}$ \\
\hline 3. & $\begin{array}{l}\text { Standarisasi definisi } \\
\text { yang digunakan } \\
\text { (Dokumen definisi } \\
\text { yang digunakan }\end{array}$ & $\sqrt{ }$ & $\begin{array}{l}\text { Prosedur tetap simbol dan } \\
\text { tanda pada dokumen rekam } \\
\text { medis Nomor } \\
\text { 05/Protap/00/A-016 tahun } \\
2011\end{array}$ \\
\hline 4. & $\begin{array}{l}\text { Standarisasi simbol } \\
\text { yang digunakan dan } \\
\text { yang tidak boleh } \\
\text { digunakan } \\
\text { didentifikasi dan } \\
\text { dimonitor. } \\
\text { (Dokumen simbol, } \\
\text { termasuk yang tidak } \\
\text { boleh digunakan) }\end{array}$ & $\sqrt{ }$ & $\begin{array}{l}\text { Prosedur tetap simbol dan } \\
\text { tanda pada dokumen rekam } \\
\text { medis Nomor } \\
\text { 05/Protap/00/A-016 tahun } \\
\text { 2011 }\end{array}$ \\
\hline 5 & $\begin{array}{l}\text { Standarisasi } \\
\text { singkatan yang } \\
\text { digunakan dan yang } \\
\text { tidak boleh } \\
\text { digunakan } \\
\text { diidentifikasi dan } \\
\text { dimonitor } \\
\text { (Dokumen singkatan } \\
\text { termasuk yang tidak } \\
\text { boleh digunakan) }\end{array}$ & $\sqrt{ }$ & $\begin{array}{l}\text { Prosedur tetap singkatan } \\
\text { diagnosis penyakit pada } \\
\text { dokumen rekam medis } \\
\text { Nomor 05/Protap/00/A- } \\
017 \text { tahun } 2011\end{array}$ \\
\hline
\end{tabular}


Diagnosis penyakit rawat jalan pada bulan Juni 2016, yang telah dilakukan pengodean mencapai 78,6 \% (9.157 dari 11.647 diagnosis), terdiri dari berpenjamin JKN sebesar 75,4 \% (8.782 dari 8.852 diagnosis) dan berpenjamin non JKN sebesar 3,2 \% (375 dari 2.795 diagnosis). Berikut tabel terakit pelaksanaan pengodean:

Tabel 2 Data Hasil Pelaksanaan Pengodean Diagnosis Penyakit Pasien Rawat Jalan JKN dan non JKN

\begin{tabular}{|c|c|c|c|c|c|}
\hline & \multicolumn{3}{|c|}{ Jumlah } & \multicolumn{2}{|c|}{ Persentase (\%) } \\
\hline & Dikode & $\begin{array}{l}\text { Tidak } \\
\text { kode }\end{array}$ & & Dikode & $\begin{array}{c}\text { Tidak } \\
\text { dikode }\end{array}$ \\
\hline $\begin{array}{l}\text { Pasien } \\
\text { Rawat } \\
\text { Jalan } \\
\text { JKN }\end{array}$ & 8.782 & 70 & 8.852 & $75,4 \%$ & $0,6 \% \quad 76,0 \%$ \\
\hline $\begin{array}{l}\text { Pasien } \\
\text { Rawat } \\
\text { Jalan } \\
\text { Non } \\
\text { JKN } \\
\end{array}$ & 375 & 2.420 & 2.795 & $3,2 \%$ & $20,8 \% \quad 24,0 \%$ \\
\hline Jumlah & 9.157 & 2.490 & 11.647 & $78,6 \%$ & $21,4 \%$ \\
\hline
\end{tabular}

Pengodean merupakan tindakan yang paling penting. Hal ini dikarenakan kualitas dari data yang dikode sangat penting bagi fasilitas pelayanan kesehatan. ${ }^{11}$ Oleh karena itu, setelah mengetahui teori di atas bahwasannya pelaksanaan pengodean itu sangat penting dan hasil pengodean itu menggambarkan kualitas manajemen Instalasi Rekam Medis.

Penerapan pengodean sistem ICD digunakan untuk mengindeks pencatatan penyakit dan tindakan di sarana pelayanan kesehatan, masukan bagi sistem pelaporan diagnosis media dan digunakan untuk pelaporan nasional dan internasional morbiditas dan mortalitas. ${ }^{11}$ Jika klasifikasi penyakit tidak dilakukan dan tidak menggunakan standar yang baku, maka perbandingan pola penyakit dari waktu ke waktu dan antar tempat tidak bisa dilakukan.

Man (SDM): Petugas pelaksana pengodean diagnosis belum sesuai kualifikasi jabatan karena masih ada perawat yang melakukan pengodean. Salah satu wewenang Ahli Madya Rekam Medis dan Informasi Kesehatan adalah melaksanakan sistem klasifikasi dan kodefikasi penyakit yang berkaitan dengan kesehatan dan tindakan medis sesuai terminologi medis yang benar. ${ }^{3}$

Selain itu belum adanya pembagian job description dari kepala Instalasi Rekam medis terkait siapa yang melakukan pengodean rawat jalan JKN dan non JKN. Kepala di unit rekam medis berperan sangat penting dalam fungsi perencanaan, bertanggungjawab langsung dan membawa seluruh stafnya untuk bekerja dalam tim kerja yang ditetapkan. ${ }^{3}$ Tujuan proses penyelenggaraan kerja tim adalah relatif dinamis. sehingga peran kepala Instalasi sangat penting, khususnya dalam pembagian job description tersebut.

Selanjutnya yang menjadi faktor penghambat yaitu petugas coding dan perawat masih kesulitan membaca beberapa 
tulisan dokter. Apabila dokter dalam menuliskan diagnosa penyakit tidak jelas dan tidak tepat maka kode yang dihasilkan oleh petugas rekam medis pun menjadi kurang tepat. $^{12}$

Method (cara): belum ada SPO terkait pengodean diagnosis penyakit rawat jalan non JKN. Standard Operating Procedure (SOP) adalah satu set instruksi tertulis yang digunakan untuk kegiatan rutin atau aktivitas yang berulang kali dilakukan oleh sebuah organisasi. $^{13}$

Material (bahan): perawat melakukan pengodean diagnosis menggunakan buku bantu yang berisi kode-kode yang sering muncul dan ditulis dokter. Namun penggunaan buku bantu tersebut belum ada aturan yang memayungi atau mengatur terkait pemberlakuan buku bantu tersebut.

SK atau surat keputusan umumnya merupakan dasar hukum dari sebuah tindakan, kegiatan, kondisi ataupun fungsi status dari pada sesuatu atau bagi seseorang yang dijadikan legal aspek untuk menetapkan atau mempertahankan sesuatu yang diputuskan tersebut. ${ }^{14}$

Salah satu faktor yang menghambat dari segi machine: SIMRS nya masih terlalu ribet. Machine atau mesin atau alat digunakan untuk memberi kemudahan atau menghasilkan keuntungan yang lebih besar serta menciptakan efisiensi kerja ${ }^{2}$. Tidak adanya penilaian kinerja pegawai, khususnya petugas coding, jadi petugas coding yang dari segi kualitas kinerjanya bagus tidak mendapatkan reward dalam bentuk apapun. Hal tersebut dikarenakan belum ada wacana terkait sistem itu, saat ini yang ada yaitu tunjangan. Salah satu cara manajemen untuk meningkatkan prestasi kerja, motivasi dan meningkatkan kinerja para karyawan adalah melalui remunerasi atau kompensasi. ${ }^{15}$

\section{KESIMPULAN}

Petugas yang melakukan pengodean rawat jalan belum sesuai dengan kualifikasi jabatan karena dilakukan oleh perawat. Kebijakan terkait pengodean rawat jalan sudah ada dan pelaksanaannya yang sudah optimal dilakukan adalah pasien jaminan JKN, pedoman pelayanan rekam medis terkait pengodean dan kualifikasi jabatan sudah ada dan pelaksanaannya mengacu pada pedoman tersebut, tapi belum seluruhnya karena masih ada yang menggunakan buku bantu dan tanggung jawab belum seluruhnya diserahkan kepada Instalasi Rekam Medis, regulasi internal terkait tata cara pengodean rawat jalan sudah ada, tapi belum mencantumkan prosedur pengodean rawat jalan untuk pasien non, serta prosedur pengodean rawat jalan JKN sesuai SPO tentang pemberian kode diagnosis penyakit di Instalasi Rekam Medis. Pedoman pengodean perawat masih menggunakan buku bantu pengodean, tetapi belum disahkan oleh pimpinan rumah sakit. Sarana yang digunakan dalam pengodean 
rawat jalan adalah system bridging INACBG's dan SIMRS RSUD Tugurejo Provinsi Jawa Tengah. Tunjangan sudah ada berupa gaji, tunjangan profesi pendidik dan jaminan pensiun dan untuk penilaian kinerja staf belum menerapkan sistem reward dan punishment.

Semua elemen penilaian pada MKI. 13 yang mengacu pada standar akreditasi KARS 2012 sudah terpenuhi dan rumah sakit sudah dinyatakan lulus akeditasi tipe B pendidikan tingkat paripurna. Persentase pelaksanaan pengodean diagnosis penyakit rawat jalan sebesar $78,6 \%$ dengan persentase sebesar 75,4 \% untuk pasien jaminan JKN dan 3,2 \% untuk pasien jaminan non JKN. Hambatan pelaksanaan pengodean diagnosis penyakit pada pasien rawat jalan. Petugas pelaksana pengodean tidak sesuai dengan kualifikasi jabatan, belum adanya pembagian job description di Instalasi Rekam medis dari Kepala Instalasi Rekam Medis dan petugas coding dan perawat masih kesulitan membaca tulisan dokter. Belum adanya SPO terkait pelaksanaan pengodean diagnosis penyakit rawat jalan non JKN. Tidak ada aturan atau SK yang mengatur pemberlakuan buku bantu. Teknik penggunaan SIMRS terlalu ribet. Belum menerapkan sistem reward dan punishment untuk penilaian kinerja staf.

Sarannya yaitu sebaiknya dibuatkan jadwal dan dilakukan supervisi dari pimpinan untuk ketertiban pelaksanaan pengodean, khususnya yang non JKN. Sebaiknya aturan terkait pelaksanaan pengodean rawat jalan diperjelas, agar tidak terjadi kesenjangan antara pasien rawat jalan JKN dan non JKN. Sebaiknya dilakukan evaluasi job description petugas coding rawat jalan dan kewenangannya terkait pelaksanaan pengodean diagnosis penyakit rawat jalan JKN dan non JKN. Sebaiknya dilakukan evaluasi pemberlakuan dan penggunaan buku bantu sebagai dasar pedoman pengodean yang dilakukan oleh petugas rekam medis, bukan perawat. Sebaiknya Kepala Instalasi Rekam Medis mengusulkan ke pimpinan rumah sakit agar penjamin mutu internal rumah sakit di setiap unit melakukan penilaian kinerja staf dengan reward dan punishment.

\section{KEPUSTAKAAN}

1. Republik Indonesia. 2009. Undangundang No. 44 Tahun 2009 Tentang Rumah sakit. Jakarta: Sekretariat Negara.

2. Arifin, M. (2012). 5M Dalam Manajemen. Tersedia dalam: http://indonesianpublichealth.blogspot.co $\mathrm{m}$ [Diakses tanggal 15 Agustus 2016 pukul 23.10 WIB].

3. Republik Indonesia. 2013. Peraturan Menteri Kesehatan No. 55 Tahun 2013 Tentang Penyelenggaraan Pekerjaan Perekam Medis. Jakarta: Menteri Kesehatan.

4. Republik Indonesia. $2014 . \quad$ Undangundang No. 38 Tahun 2014 Tentang Keperawatan. Jakarta: Sekretariat Negara.

5. Suharto, Edi. 2008. Analisis Kebijakan Publik. Bandung: Alfabeta. Sydney: WB. Sauders Company. 
6. Republik Indonesia. 2011. Peraturan Menteri Kesehatan No.No. 1538 Tahun 2011 tentang Pedoman Tata Naskah Dinas di Lingkungan Kementerian Kesehatan. Jakarta: Menteri Kesehatan.

7. Republik Indonesia. 1998. Keputusan Menteri Kesehatan Republik Indonesia Nomor 50/MENKES/SK/I/1998 tentang Pemberlakuan Klasifikasi Statistik Internasional Mengenai Penyakit Revisi Kesepuluh, yaitu memberlakukan klasifikasi. Jakarta: Menteri Kesehatan.

8. Keputusan Konsil Kedokteran Indonesia. 2006. Konsil Kedokteran Indonesia No. 16 Tahun 2006 tentang Manual Rekam Medis. Jakarta: Ketua Konsil Kedokteran Indonesia.

9. Simanjuntak, Payaman J. 2005. Manajemen dan Evaluasi Kinerja. Jakarta: FE UI.

10. Kemenkes RI. 2011, Standar Akreditasi Rumah Sakit, Kerjasama Direktorat Jenderal Bina Upaya Kesehatan Kementerian Kesehatan Republik
Indonesia dengan Komisi Akreditasi Rumah Sakit (KARS). Jakarta: KARS.

11. Hatta, Gemala. 2010. Pedoman Manajemen Informasi Kesehatan di Sarana Pelayanan Kesehatan. Jakarta: Universitas Indonesia.

12. Purwono, Dwi. 2007. Pelaksanaan Coding Diagnosis Utama Pasien Rawat Inap di Rumah Sakit Jiwa Prof. Dr. Soeroyo Magelang. Karya Tulis IImiah. D3 Rekam Medis Dan Informasi Kesehatan UGM. (Tidak Dipublikasikan).

13. Hartatik, Indah Puji. 2014. Buku Pintar Membuat S.O.P. Yogyakarta: Flashbooks.

14. Tahar, Herikasni. 2013. Pengertian surat keputusan. Tersedia dalam: http://herikasnitahar.blogspot.co.id.

[Diakses tanggal 10 Agustus 2016 pukul 12.49 WIB].

15. Matchis, Jackson. 2002. Manajemen Sumber Daya Manusia. Jakarta: Salemba Empat. 